ISSN 2078-3744. Вісник Львів. ун-ту. Серія мех.-мат. 2019. Випуск 87. С. 73-81

Visnyk of the Lviv Univ. Series Mech. Math. 2019. Issue 87. P. 73-81

http://publications.lnu.edu.ua/bulletins/index.php/mmf

doi: http://dx.doi.org/10.30970/vmm.2019.87.073-081

УДК 517.537 .72

\title{
REMARKS TO RELATIVE GROWTH OF ENTIRE DIRICHLET SERIES
}

\author{
Oksana MULYAVA $^{1}$, Myroslav SHEREMETA ${ }^{2}$ \\ ${ }^{1}$ Kyiv National University of Food Technologies, \\ Volodymyrska Str., 68, 01004, Kyiv, Ukraine \\ e-mail: oksana.m@bigmir.net \\ ${ }^{2}$ Ivan Franko National University of Lviv, \\ Universytetska Str., 1, 79000, Lviv, Ukraine \\ e-mail: m.m.sheremeta@gmail.com
}

Let $F$ and $G$ be entire functions given by Dirichlet series with exponents increasing to $+\infty$ and $\varrho_{R}[F]_{G}$ be the $R$-order of $F$ with respect to a function $G$. The quantities

$T_{R}[F]_{G}:=\varlimsup_{\sigma \rightarrow+\infty} \frac{\exp \left\{M_{G}^{-1}\left(M_{F}(\sigma)\right)\right\}}{\exp \left\{\varrho_{R}[F]_{G} \sigma\right\}}, \quad t_{R}[F]_{G}:=\lim _{\sigma \rightarrow+\infty} \frac{\exp \left\{M_{G}^{-1}\left(M_{F}(\sigma)\right)\right\}}{\exp \left\{\varrho_{R}[F]_{G} \sigma\right\}}$ are called the $R$-type and the lower $R$-type of $F$ with respect to $G$. A connection between $T_{R}[F]_{G}, t_{R}[F]_{G}$ and the $R$-types and the lower $R$-types of $F$ and $G$ is demonstrated.

Key words: Dirichlet series, relative growth, convergence class

\section{INTRODUCTION}

Let $f$ and $g$ be entire transcendental functions and $M_{f}(r)=\max \{|f(z)|:|z|=r\}$. For the study of relative growth of the functions $f$ and $g$ Ch. Roy [1] used the order $\varrho_{g}[f]=\varlimsup_{r \rightarrow+\infty} \frac{\ln M_{g}^{-1}\left(M_{f}(r)\right)}{\ln r}$ and the lower order $\lambda_{g}[f]=\lim _{r \rightarrow+\infty} \frac{\ln M_{g}^{-1}\left(M_{f}(r)\right)}{\ln r}$ of the function $f$ with respect to the function $g$. Research of relative growth of entire functions was continued by T. Biswas and other mathematicians (see, for example, [2], 3]).

Suppose that $\Lambda=\left(\lambda_{n}\right)$ is an increasing to $+\infty$ sequence of non-negative numbers, and Dirichlet series

$$
F(s)=\sum_{n=1}^{\infty} f_{n} \exp \left\{s \lambda_{n}\right\}, \quad s=\sigma+i t
$$

2010 Mathematics Subject Classification: 30B50

(C) Mulyava, O., Sheremeta, M., 2019 
has the abscissa of absolute convergence $\sigma_{a}=+\infty$. For $\sigma<+\infty$ we put $M_{F}(\sigma)=$ $=\sup \{|F(\sigma+i t)|: t \in \mathbb{R}\}$.

Let $L$ be a class of continuous non-negative on $(-\infty,+\infty)$ functions $\alpha$ such that $\alpha(x)=\alpha\left(x_{0}\right) \geq 0$ for $x \leq x_{0}$ and $\alpha(x) \uparrow+\infty$ as $x \rightarrow+\infty$. We say that $\alpha \in L^{0}$, if $\alpha \in L$ and $\alpha((1+o(1)) x)=(1+o(1)) \alpha(x)$ as $x \rightarrow+\infty$. Finally, $\alpha \in L_{s i}$, if $\alpha \in L$ and $\alpha(c x)=(1+o(1)) \alpha(x)$ as $x_{0} \leq x \rightarrow+\infty$ for each $c \in(0,+\infty)$, i. e. $\alpha$ is a slowly increasing function. Clearly, $L_{s i} \subset L^{0}$.

If $\alpha \in L$ and $\beta \in L$ then for entire Dirichlet series (1) the quantities

$$
\varrho_{\alpha, \beta}[F]=\varlimsup_{\sigma \rightarrow+\infty} \frac{\alpha\left(\ln M_{F}(\sigma)\right)}{\beta(\sigma)}, \quad \lambda_{\alpha, \beta}[F]=\varliminf_{\sigma \rightarrow+\infty} \frac{\alpha\left(\ln M_{F}(\sigma)\right)}{\beta(\sigma)}
$$

are called the generalized order and the generalized lower order of $F$, respectively. We say that $F$ has the generalized regular growth, if $0<\lambda_{\alpha, \beta}[F]=\varrho_{\alpha, \beta}[F]<+\infty$.

As in [4] we define the generalized order $\varrho_{\alpha, \beta}[F]_{G}$ and the generalized lower order $\lambda_{\alpha, \beta}[F]_{G}$ of the function $F$ with respect to a function $G$, given by an entire Dirichlet series

$$
G(s)=\sum_{n=1}^{\infty} g_{n} \exp \left\{s \lambda_{n}\right\}
$$

as follows

$$
\varrho_{\alpha, \beta}[F]_{G}=\varlimsup_{\sigma \rightarrow+\infty} \frac{\beta\left(M_{G}^{-1}\left(M_{F}(\sigma)\right)\right)}{\beta(\sigma)}, \quad \lambda_{\alpha, \beta}[F]_{G}=\lim _{\sigma \rightarrow+\infty} \frac{\beta\left(M_{G}^{-1}\left(M_{F}(\sigma)\right)\right)}{\beta(\sigma)} .
$$

The following two theorems are proved in 4 .

Theorem A. Let $\alpha \in L$ and $\beta \in L$. Except for the cases when $\varrho_{\alpha, \beta}[F]=\varrho_{\alpha, \beta}[G]=0$ or $\varrho_{\alpha, \beta}[F]=\varrho_{\alpha, \beta}[G]=+\infty$, the inequality $\varrho_{\alpha, \beta}[F]_{G} \geq \varrho_{\alpha, \beta}[F] / \varrho_{\alpha, \beta}[G]$ is true and subject to the condition of the regular growth of $G$ this inequality converts into an equality.

Except for the cases when $\lambda_{\alpha, \beta}[F]=\lambda_{\alpha, \beta}[G]=0$ or $\lambda_{\alpha, \beta}[F]=\lambda_{\alpha, \beta}[G]=+\infty$, the inequality $\lambda_{\alpha, \beta}[F]_{G} \leq \lambda_{\alpha, \beta}[F] / \lambda_{\alpha, \beta}[G]$ is true and subject to the condition of the regular growth of $G$ this inequality converts into an equality.

Theorem B. Let $0<p<+\infty$ and one of conditions is satisfied:

a) $\alpha \in L^{0}, \beta(\ln x) \in L^{0}, \frac{d \beta^{-1}(c \alpha(x))}{d \ln x} \rightarrow \frac{1}{p}(x \rightarrow+\infty)$ for each $c \in(0,+\infty)$ and $\ln n=o\left(\lambda_{n}\right)(n \rightarrow \infty)$;

b) $\alpha \in L_{s i}, \beta \in L^{0}, \varrho_{\alpha, \beta}[F]<+\infty, \frac{d \beta^{-1}(c \alpha(x))}{d \ln x}=O(1)(x \rightarrow+\infty)$ and $\ln n=$ $=o\left(\lambda_{n} \beta^{-1}\left(c \alpha\left(\lambda_{n}\right)\right)\right)(n \rightarrow \infty)$ for each $c \in(0,+\infty)$.

Suppose that $\alpha\left(\lambda_{n+1} / p\right)=(1+o(1)) \alpha\left(\lambda_{n} / p\right)$ as $n \rightarrow \infty$.

If the function $G$ has generalized regular growth and

$$
\varkappa_{n}[G]:=\frac{\ln \left|g_{n}\right|-\ln \left|g_{n+1}\right|}{\lambda_{n+1}-\lambda_{n}} \nearrow+\infty, \quad n_{0} \leq n \rightarrow \infty,
$$


then

$$
\varrho_{\alpha, \beta}[F]_{G}=\varlimsup_{n \rightarrow \infty} \frac{\beta\left(\frac{1}{p}+\frac{1}{\lambda_{n}} \ln \frac{1}{\left|g_{n}\right|}\right)}{\beta\left(\frac{1}{p}+\frac{1}{\lambda_{n}} \ln \frac{1}{\left|f_{n}\right|}\right)}
$$

except for the cases when $\varrho_{\alpha, \beta}[F]=\varrho_{\alpha, \beta}[G]=0$ or $\varrho_{\alpha, \beta}[F]=\varrho_{\alpha, \beta}[G]=+\infty$.

If, moreover, $F$ has generalized regular growth and $\varkappa_{n}[F] \nearrow+\infty$ as $n_{0} \leq n \rightarrow \infty$ then

$$
\lambda_{\alpha, \beta}[F]_{G}=\lim _{n \rightarrow \infty} \frac{\beta\left(\frac{1}{p}+\frac{1}{\lambda_{n}} \ln \frac{1}{\left|g_{n}\right|}\right)}{\beta\left(\frac{1}{p}+\frac{1}{\lambda_{n}} \ln \frac{1}{\left|f_{n}\right|}\right)}
$$

except for the cases when $\lambda_{\alpha, \beta}[F]=\lambda_{\alpha, \beta}[G]=0$ or $\lambda_{\alpha, \beta}[F]=\lambda_{\alpha, \beta}[G]=+\infty$.

If we choose $\alpha(x)=\ln x$ and $\beta(x)=x$ for $x \geq 3$ then from the definition of $\varrho_{\alpha, \beta}[F]$ and $\lambda_{\alpha, \beta}[F]$ we obtain the definition of the $R$-order $\varrho_{R}[F]$ and the lower $R$-order $\lambda_{R}[F]$. The quantities

$$
\varrho_{R}[F]_{G}:=\varlimsup_{\sigma \rightarrow+\infty} \frac{M_{G}^{-1}\left(M_{F}(\sigma)\right)}{\sigma}, \quad \lambda_{R}[F]_{G}:=\lim _{\sigma \rightarrow+\infty} \frac{M_{G}^{-1}\left(M_{F}(\sigma)\right)}{\sigma}
$$

we will call the $R$-order and the lower $R$-order of $F$ with respect to a function $G$, accordingly. From Theorems A and B we get the following statement.

Corollary 1. Except for the cases when $\varrho_{R}[F]=\varrho_{R}[G]=0$ or $\varrho_{R}[F]=\varrho_{R}[G]=+\infty$, the inequality $\varrho_{R}[F]_{G} \geq \varrho_{R}[F] / \varrho_{R}[G]$ is true and subject to the condition of the regular growth of $G$ (i.e. $\left.0<\lambda_{R}[G]=\lambda_{R}[G]<\infty\right)$ this inequality converts into an equality, and except for the cases when $\lambda_{R}[F]=\lambda_{R}[G]=0$ or $\lambda_{R}[F]=\lambda_{R}[G]=+\infty$, the inequality $\lambda_{R}[F]_{G} \leq \lambda_{R}[F] / \lambda_{R}[G]$ is true and subject to the condition of the regular growth of $G$ this inequality converts into an equality.

If $\ln n=o\left(\lambda_{n} \ln \lambda_{n}\right), \ln \lambda_{n+1}=(1+o(1)) \ln \lambda_{n}$ as $n \rightarrow \infty$, the function $G$ has the regular growth and $\varkappa_{n}[G] \nearrow+\infty$ as $n_{0} \leq n \rightarrow \infty$ then $\varrho_{R}[F]_{G}=\varlimsup_{n \rightarrow \infty} \frac{\ln \left|g_{n}\right|}{\ln \left|f_{n}\right|}$ except for the cases when $\varrho_{R}[F]=\varrho_{R}[G]=0$ or $\varrho_{R}[F]=\varrho_{R}[G]=+\infty$, and if, moreover, the function $F$ has the regular growth and and $\varkappa_{n}[F] \nearrow+\infty$ as $n_{0} \leq n \rightarrow \infty$ then $\lambda_{R}[F]_{G}=$ $=\varliminf_{n \rightarrow \infty} \frac{\ln \left|g_{n}\right|}{\ln \left|f_{n}\right|}$ except for the cases when $\lambda_{R}[F]=\lambda_{R}[G]=0$ or $\lambda_{R}[F]=\lambda_{R}[G]=+\infty$.

Here we investigate the growth of $F$ with respect to $G$ in terms of $R$-types and convergence classes.

\section{Relative GROWth IN TERMS OF $R$-TyPeS}

Suppose that $\varrho_{R}[F]=\varrho \in(0,+\infty)$. If we choose $\alpha(x)=x$ and $\beta(x)=e^{\varrho x}$ for $x \geq 1$ then from the definition of $\varrho_{\alpha, \beta}[F]$ and $\lambda_{\alpha, \beta}[F]$ we obtain the definition of the $R$-type $T_{R}[F]$ and the lower $R$-type $t_{R}[F]$. Similarly, the quantities

$$
T_{R}[F]_{G}:=\varlimsup_{\sigma \rightarrow+\infty} \frac{\exp \left\{M_{G}^{-1}\left(M_{F}(\sigma)\right)\right\}}{\exp \left\{\varrho_{R}[F]_{G} \sigma\right\}}, \quad t_{R}[F]_{G}:=\varliminf_{\sigma \rightarrow+\infty} \frac{\exp \left\{M_{G}^{-1}\left(M_{F}(\sigma)\right)\right\}}{\exp \left\{\varrho_{R}[F]_{G} \sigma\right\}}
$$


are called the $R$-type and the lower $R$-type of $F$ with respect to $G$, respectively.

The following two statements cannot be derived from Theorems A and B, but are their analogues.

Proposition 1. Suppose that the function $G$ has regular growth. Then except for the cases when $T_{R}[F]=T_{R}[G]=0$ or $T_{R}[F]=T_{R}[G]=+\infty$, the inequality $T_{R}[F]_{G} \geq$ $\geq\left(T_{R}[F] / T_{R}[G]\right)^{1 / \varrho_{R}[G]}$ is true and subject to the condition of the strongly regular growth of $G$ (i. e. $\left.0<t_{R}[G]=T_{R}[G]<\infty\right)$ this inequality converts into an equality, and except for the cases when $t_{R}[F]=t_{R}[G]=0$ or $t_{R}[F]=t_{R}[G]=+\infty$, the inequality $t_{R}[F]_{G} \leq\left(t_{R}[F] / t_{R}[G]\right)^{1 / \varrho_{R}[G]}$ and subject to the condition of the strongly regular growth of $G$ this inequality converts into an equality.

Proof. Since $G$ has the regular growth, from Corollary 1 we get $\varrho_{R}[F]_{G}=\varrho_{R}[F] / \varrho_{R}[G]$. Therefore,

$$
T_{R}[F]_{G}=\varlimsup_{\sigma \rightarrow+\infty} \frac{\exp \left\{M_{G}^{-1}\left(M_{F}(\sigma)\right)\right\}}{\exp \left\{\frac{\varrho_{R}[F]}{\varrho_{R}[G]} \sigma\right\}}=\varlimsup_{\sigma \rightarrow+\infty}\left(\frac{\exp \left\{\varrho_{R}[G] M_{G}^{-1}\left(M_{F}(\sigma)\right)\right\}}{\exp \left\{\varrho_{R}[F] \sigma\right\}}\right)^{1 / \varrho_{R}[G]},
$$

i.e.

$$
\begin{aligned}
\left(T_{R}[F]_{G}\right)^{\varrho_{R}[G]} & =\varlimsup_{x \rightarrow+\infty} \frac{\exp \left\{\varrho_{R}[G] M_{G}^{-1}(x)\right\}}{\exp \left\{\varrho_{R}[F] M_{F}^{-1}(x)\right\}} \geq \\
& \geq \varlimsup_{x \rightarrow+\infty} \frac{\ln x}{\exp \left\{\varrho_{R}[F] M_{F}^{-1}(x)\right\}} \underset{x \rightarrow+\infty}{\underline{\lim }} \frac{\exp \left\{\varrho_{R}[G] M_{G}^{-1}(x)\right\}}{\ln x}= \\
& =\varlimsup_{\sigma \rightarrow+\infty} \frac{\ln M_{F}(\sigma)}{\exp \left\{\varrho_{R}[F] \sigma\right\}} \underset{\sigma \rightarrow+\infty}{\frac{\lim }{\ln M_{G}(\sigma)}=} \\
& =\frac{T_{R}[F]}{T_{R}[G]} .
\end{aligned}
$$

If $G$ has the strongly regular growth then there exists $\lim _{\sigma \rightarrow+\infty} \frac{\ln M_{G}(\sigma)}{\exp \left\{\varrho_{R}[G] \sigma\right\}}$ and as above we have

$$
\begin{aligned}
\left(T_{R}[F]_{G}\right)^{\varrho_{R}[G]} & =\varlimsup_{x \rightarrow+\infty} \frac{\exp \left\{\varrho_{R}[G] M_{G}^{-1}(x)\right\}}{\exp \left\{\varrho_{R}[F] M_{F}^{-1}(x)\right\}}= \\
& =\varlimsup_{x \rightarrow+\infty} \frac{\ln x}{\exp \left\{\varrho_{R}[F] M_{F}^{-1}(x)\right\}} \lim _{x \rightarrow+\infty} \frac{\exp \left\{\varrho_{R}[G] M_{G}^{-1}(x)\right\}}{\ln x}= \\
& =\frac{T_{R}[F]}{T_{R}[G]} .
\end{aligned}
$$

The first part of Proposition 1 is proved.

The proof of second part is similar. Indeed,

$$
\begin{aligned}
\left(t_{R}[F]_{G}\right)^{\varrho_{R}[G]} & =\lim _{x \rightarrow+\infty} \frac{\exp \left\{\varrho_{R}[G] M_{G}^{-1}(x)\right\}}{\exp \left\{\varrho_{R}[F] M_{F}^{-1}(x)\right\}} \leq \\
& \leq \varliminf_{x \rightarrow+\infty} \frac{\ln x}{\exp \left\{\varrho_{R}[F] M_{F}^{-1}(x)\right\}} \varlimsup_{x \rightarrow+\infty} \frac{\exp \left\{\varrho_{R}[G] M_{G}^{-1}(x)\right\}}{\ln x}=
\end{aligned}
$$




$$
\begin{aligned}
& =\varliminf_{\sigma \rightarrow+\infty} \frac{\ln M_{F}(\sigma)}{\exp \left\{\varrho_{R}[F] \sigma\right\}} \varlimsup_{\sigma \rightarrow+\infty} \frac{\exp \left\{\varrho_{R}[G] \sigma\right\}}{\ln M_{G}(\sigma)}= \\
& =\frac{t_{R}[F]}{t_{R}[G]}
\end{aligned}
$$

and if there exists $\lim _{\sigma \rightarrow+\infty} \frac{\ln M_{G}(\sigma)}{\exp \left\{\varrho_{R}[G] \sigma\right\}}=t_{R}[F]=T_{R}[F]$ then

$$
\left(t_{R}[F]_{G}\right)^{\varrho_{R}[G]}=\varliminf_{x \rightarrow+\infty} \frac{\ln x}{\exp \left\{\varrho_{R}[F] M_{F}^{-1}(x)\right\}} \varlimsup_{x \rightarrow+\infty} \frac{\exp \left\{\varrho_{R}[G] M_{G}^{-1}(x)\right\}}{\ln x}=\frac{t_{R}[F]}{t_{R}[G]} .
$$

To get the analogue of theorem $\mathrm{B}$ we use thefollowing lemma following which can be obtained from Lemma 1 in [4], if we will choose $\alpha(x)=x$ and $\beta(x)=e^{\varrho x}$ for $x \geq 1$.

Lemma 1. Suppose that for entire Dirichlet series (1) $\ln n=o\left(\lambda_{n}\right)$ as $n \rightarrow \infty$. Then $T_{R}[F]=\varlimsup_{n \rightarrow \infty} \frac{\lambda_{n}}{e \varrho_{R}[F]}\left|f_{n}\right|^{\varrho_{R}[F] / \lambda_{n}}$, and if, moreover, $\lambda_{n+1}=(1+o(1)) \lambda_{n}$ and $\varkappa_{n}[F] \nearrow+\infty$ as $n_{0} \leq n \rightarrow \infty$ then $t_{R}[F]=\varliminf_{n \rightarrow \infty} \frac{\lambda_{n}}{e \varrho_{R}[F]}\left|f_{n}\right|^{\varrho_{R}[F] / \lambda_{n}}$.

Proposition 2. Suppose that the exponents of entire Dirichlet series (1) and (2) satisfy the conditions $\ln n=o\left(\lambda_{n}\right)$ and $\lambda_{n+1}=(1+o(1)) \lambda_{n}$ as $n \rightarrow \infty$.

If the function $G$ has the strongly regular growth and $\varkappa_{n}[G] \nearrow+\infty$ as $n_{0} \leq n \rightarrow \infty$ then

$$
\left(T_{R}[F]_{G}\right)^{\varrho_{R}[G]}=k^{*}:=\frac{\varrho_{R}[G]}{\varrho_{R}[F]} \varlimsup_{n \rightarrow \infty} \frac{\left|f_{n}\right|^{\varrho_{R}[F] / \lambda_{n}}}{\left|g_{n}\right|^{\varrho_{R}[G] / \lambda_{n}}}
$$

except for the cases when $T_{R}[F]=T_{R}[G]=0$ or $T_{R}[F]=T_{R}[G]=+\infty$.

If, moreover, the function $F$ has the strongly regular growth and $\varkappa_{n}[F] \nearrow+\infty$ as $n_{0} \leq n \rightarrow \infty$ then

$$
\left(t_{R}[F]_{G}\right)^{\varrho_{R}[G]}=k_{*}:=\frac{\varrho_{R}[G]}{\varrho_{R}[F]} \varliminf_{n \rightarrow \infty} \frac{\left|f_{n}\right|^{\varrho_{R}[F] / \lambda_{n}}}{\left|g_{n}\right|^{\varrho_{R}[G] / \lambda_{n}}}
$$

except for the cases when $t_{R}[F]=t_{R}[G]=0$ or $t_{R}[F]=t_{R}[G]=+\infty$.

Proof. By Proposition 1 and Lemma 1 we have

$$
\begin{aligned}
& \left(T_{R}[F]_{G}\right)^{\varrho_{R}[F]_{G}}=\frac{T_{R}[F]}{T_{R}[G]}=\varlimsup_{n \rightarrow \infty} \frac{\lambda_{n}}{e \varrho_{R}[F]}\left|f_{n}\right|^{\varrho_{R}[F] / \lambda_{n}} \varliminf_{n \rightarrow \infty} \frac{e \varrho_{R}[G]}{\lambda_{n}\left|f_{n}\right|^{\varrho_{R}[G] / \lambda_{n}}} \leq \\
& \leq \varlimsup_{n \rightarrow \infty} \frac{\lambda_{n}}{e \varrho_{R}[F]}\left|f_{n}\right|^{\varrho_{R}[F] / \lambda_{n}} \frac{e \varrho_{R}[G]}{\lambda_{n}\left|f_{n}\right|^{\varrho_{R}[G] / \lambda_{n}}}=\frac{\varrho_{R}[G]}{\varrho_{R}[F]} \varlimsup_{n \rightarrow \infty} \frac{\left|f_{n}\right|^{\varrho_{R}[F] / \lambda_{n}}}{\left|g_{n}\right|^{\varrho_{R}[G] / \lambda_{n}}}=k^{*} .
\end{aligned}
$$

On the other hand, let $k^{*}>0$. Then for every $\varepsilon \in\left(0, k^{*}\right)$ there exists an increasing to $\infty$ sequence $\left(n_{k}\right)$ of integers such that

$$
\frac{\left|f_{n_{k}}\right|^{\varrho_{R}[F] / \lambda_{n_{k}}}}{\varrho_{R}[F]}>\left(k^{*}-\varepsilon\right) \frac{\left|g_{n_{k}}\right| \varrho_{R}[G] / \lambda_{n_{k}}}{\varrho_{R}[G]}
$$


and, thus,

$$
\varlimsup_{n \rightarrow \infty} \frac{\lambda_{n}}{e \varrho_{R}[F]}\left|f_{n}\right|^{\varrho_{R}[F] / \lambda_{n}}>\left(k^{*}-\varepsilon\right) \varliminf_{n \rightarrow \infty} \frac{\lambda_{n}\left|g_{n}\right| \varrho_{R}[G] / \lambda_{n}}{e \varrho_{R}[G]} .
$$

Since $G$ has the strongly regular growth, that is $T_{R}[G]=t_{R}[G]$, hence by Lemma 1 we obtain the inequality $T_{R}[F]>\left(k^{*}-\varepsilon\right) T_{R}[G]$, i. e. in view of arbitrariness of $\varepsilon$ the inequality $\left(T_{R}[F]_{G}\right)^{\varrho_{R}[G]}=\frac{T_{R}[F]}{T_{R}[G]} \geq k^{*}$ is true. For $k^{*}=0$ the last inequality is obvious. The first part of Proposition 2 is proved.

For the proof of the second part we remark that since the function $G$ has the strongly regular growth, by Proposition 1 and Lemma 1

$$
\begin{aligned}
& \left(t_{R}[F]_{G}\right)^{\varrho_{R}[F]_{G}}=\frac{t_{R}[F]}{t_{R}[G]}=\varliminf_{n \rightarrow \infty} \frac{\lambda_{n}}{e \varrho_{R}[F]}\left|f_{n}\right|^{\varrho_{R}[F] / \lambda_{n}} \varlimsup_{n \rightarrow \infty} \frac{e \varrho_{R}[G]}{\lambda_{n}\left|f_{n}\right| \varrho_{R}[G] / \lambda_{n}} \geq \\
& \geq \varliminf_{n \rightarrow \infty} \frac{\lambda_{n}}{e \varrho_{R}[F]}\left|f_{n}\right|^{\varrho_{R}[F] / \lambda_{n}} \frac{e \varrho_{R}[G]}{\lambda_{n}\left|f_{n}\right| \varrho_{R}[G] / \lambda_{n}}=\frac{\varrho_{R}[G]}{\varrho_{R}[F]} \underline{\lim _{n \rightarrow \infty}} \frac{\left|f_{n}\right| \varrho_{R}[F] / \lambda_{n}}{\left|g_{n}\right| \varrho_{R}[G] / \lambda_{n}}=k_{*} .
\end{aligned}
$$

On the other hand, if $k_{*}<+\infty$ then for every $\varepsilon>0$ there exists an increasing to $\infty$ sequence $\left(n_{k}\right)$ of integers such that

$$
\frac{\left|f_{n_{k}}\right| \varrho_{R}[F] / \lambda_{n_{k}}}{\varrho_{R}[F]}<\left(k_{*}+\varepsilon\right) \frac{\left|g_{n_{k}}\right| \varrho_{R}[G] / \lambda_{n_{k}}}{\varrho_{R}[G]}
$$

and, thus,

$$
\varliminf_{n \rightarrow \infty} \frac{\lambda_{n}}{e \varrho_{R}[F]}\left|f_{n}\right|^{\varrho_{R}[F] / \lambda_{n}}<\left(k_{*}+\varepsilon\right) \varlimsup_{n \rightarrow \infty} \frac{e \varrho_{R}[G]}{\lambda_{n}\left|g_{n}\right| \varrho_{R}[G] / \lambda_{n}},
$$

whence by Lemma 1 it follows that $t_{R}[F]<\left(k_{*}+\varepsilon\right) t_{R}[G]$ and in view of arbitrariness of $\varepsilon$ the inequality $\left(t_{R}[F]_{G}\right)^{\varrho_{R}[G]}=\frac{t_{R}[F]}{t_{R}[G]} \leq k_{*}$ is true. The last inequality is trivial, if $k_{*}=+\infty$. The proof of Proposition 2 is completed.

We remark that if $\varrho_{R}[F]_{G}=\varrho_{R}[F] / \varrho_{R}[G]$ then the $R$-type and the lower $R$-type of $F$ with respect to $G$ can be defined also by formulas

$T_{R}^{*}[F]_{G}:=\varlimsup_{\sigma \rightarrow+\infty} \frac{\exp \left\{\varrho_{R}[G] M_{G}^{-1}\left(M_{F}(\sigma)\right)\right\}}{\exp \left\{\varrho_{R}[F] \sigma\right\}}, t_{R}^{*}[F]_{G}:=\varliminf_{\sigma \rightarrow+\infty} \frac{\exp \left\{\varrho_{R}[G] M_{G}^{-1}\left(M_{F}(\sigma)\right)\right\}}{\exp \left\{\varrho_{R}[F] \sigma\right\}}$.

Then in Proposition 1 the inequalities $T_{R}[F]_{G} \geq\left(T_{R}[F] / T_{R}[G]\right)^{1 / \varrho_{R}[G]}$ and $t_{R}[F]_{G} \leq$ $\leq\left(t_{R}[F] / t_{R}[G]\right)^{\left.1 / \varrho_{R} G\right]}$ can be replaced by the inequalities $T_{R}^{*}[F]_{G} \geq T_{R}[F] / T_{R}[G]$ and $t_{R}^{*}[F]_{G} \leq t_{R}[F] / t_{R}[G]$, and in formulae (3) and (4) instead of $\left(T_{R}[F]_{G}\right)^{\varrho_{R}[G]}$ and $\left(t_{R}[F]_{G}\right)^{\varrho_{R}[G]}$ one can put $T_{R}^{*}[F]_{G}$ and $t_{R}^{*}[F]_{G}$.

\section{Convergence Classes}

Generalizing the convergence class introduced by Valiron for entire functions, P. Kamthan [5] showed that if the sequence $\left(\lambda_{n}\right)$ has a positive finite step, that is $0<h \leq \lambda_{n+1}-\lambda_{n} \leq H<\infty$ for $n \geq 0$, and $\varkappa_{n}(F) \uparrow+\infty$ as $n \rightarrow \infty$ then in order that

$$
\int_{0}^{\infty} \frac{\ln M_{F}(\sigma)}{e^{\varrho \sigma}} d \sigma<+\infty
$$


it is necessary and sufficient that $\sum_{n=1}^{\infty}\left|f_{n}\right|^{\varrho / \lambda_{n}}<+\infty$. Giving up a condition on the step of exponents in [6] it is well-proven that if $\ln n=O\left(\lambda_{n}\right)$ as $n \rightarrow \infty$ then in order that (5) holds, it is necessary and in the case when $\varkappa_{n}(F) \nearrow+\infty(n \rightarrow \infty)$, it is sufficient that $\sum_{n=1}^{\infty}\left(\lambda_{n}-\lambda_{n-1}\right)\left|f_{n}\right|^{\varrho / \lambda_{n}}<+\infty$.

If $T_{R}[F]_{G}=0$, that is in view of the equality $T_{R}^{*}[F]_{G}=\left(T_{R}[F]_{G}\right)^{\varrho_{R}[F]_{G}}$ we get $T_{R}^{*}[F]_{G}=0$, for a characteristic of the growth of $F$ we introduce a convergence class with respect to $G$ by the condition

$$
\int_{0}^{\infty} \frac{\exp \left\{\varrho_{R}[G] M_{G}^{-1}\left(M_{F}(\sigma)\right)\right\}}{\exp \left\{\varrho_{R}[F] \sigma\right\}} d \sigma<+\infty .
$$

Proposition 3. If a function $G$ has the positive lower R-type and the finite R-type then a function $F$ belongs to the convergence class with respect to $G$ if and only if $F$ belongs to the convergence class defined by Kamthan.

For the proof of this statement it is enough to use the estimations

$$
0<t \leq \leq \frac{\ln M_{G}(\sigma)}{\exp \left\{\varrho_{R}[F] \sigma\right\}} \leq T<+\infty .
$$

As in [7, we say that an entire Dirichlet series (1) belongs to the generalized convergence $\alpha \beta$-class, if

$$
\int_{\sigma_{0}}^{\infty} \frac{\alpha\left(\ln M_{F}(\sigma)\right)}{\beta(\sigma)} d \sigma<+\infty
$$

The following theorem is proved in [7].

Theorem C. Let $\alpha$ be a concave on $\left[x_{0},+\infty\right)$ function, $\alpha\left(e^{x}\right) \in L^{0}$ and a function $\beta \in L^{0}$ satisfies conditions $x \beta^{\prime}(x) / \beta(x) \geq h>0$ for $x \geq x_{0}$ and $\int_{x_{0}}^{\infty} \frac{\alpha(x)}{\beta(x)} d x<+\infty$. Suppose that $\ln n=o\left(\lambda_{n} \beta^{-1}\left(\alpha\left(\lambda_{n}\right)\right)\right)$ as $n \rightarrow \infty$. Then in order that entire Dirichlet series (1) belongs to the generalized convergence $\alpha \beta$-class, it is necessary and in the case when $\varkappa_{n}(F) \nearrow+\infty(n \rightarrow \infty)$, it is sufficient that

$$
\sum_{n=1}^{\infty}\left(\alpha\left(\lambda_{n}\right)-\alpha\left(\lambda_{n-1}\right)\right) \beta_{1}\left(\frac{1}{\lambda_{n}} \ln \frac{1}{\left|f_{n}\right|}\right)<+\infty, \quad \beta_{1}(x)=\int_{x}^{\infty} \frac{d \sigma}{\beta(\sigma)} .
$$

Finally, in view of the definition of $\varrho_{\alpha \beta}[F]$ by the condition $\varrho_{\alpha \beta}[F]=0$ we say that $F$ belongs to a generalized convergence $\alpha \beta$-class with respect to $G$, if

$$
\int_{\sigma_{0}}^{\infty} \frac{\beta\left(M_{G}^{-1}\left(M_{F}(\sigma)\right)\right)}{\beta(\sigma)} d \sigma<+\infty .
$$

The following statement is true. 
Proposition 4. If a function $G$ has the positive generalized lower order and the finite generalized order then a function $F$ belongs to a generalized convergence $\alpha \beta$-class with respect to $G$, if and only if $F$ belongs to a generalized convergence $\alpha \beta$-class defined by condition $(6)$.

\section{REFERENCES}

1. Ch. Roy, On the relative order and lower order of an entire functiion, Bull. Calcutta Math. Soc. 102 (2010), no. 1, 17-26.

2. S. K. Data, T. Biswas, and A. Hoque, Some results on the growth analysis of entire function using their maximum terms and relative $L^{*}$-order, J. Math. Ext. 10 (2016), no. 2. 59-73.

3. S. K. Data, T. Biswas, and P. Das, Some results on generalized relative order of meromorohic functions, Уфимск. матем. журн. 8 (2016), no. 2, 97-105; reprinted version: Ufa Math. J. 8 (2016), no. 2, 93-103. DOI: 10.13108/2016-8-2-95

4. O. M. Mulyava and M. M. Sheremeta, Relative growth of Dirichlet series, Mat. Stud. 49 (2018), no. 2, 158-164. DOI: 10.15330/ms.49.2.158-164

5. P. K. Kamthan, A theorem of step functions. II, Rev. Fac. Sci. Univ. Istanbul, Ser. A 28 (1963), 65-69.

6. О. М. Мулява, Про класи збіжності рлдів Діріхле, Укр. мат. журн. 51 (1999), по. 11, 1485-1494; English version: O. M. Mulyava, On convergence classes of Dirichlet series, Ukr. Math. J. 51 (1999), no. 11, 1681-1692. DOI: 10.1007/BF02525271

7. O. M. Mulyava, Convergence classes in theory of Dirichlet series, Dopov. NAN Ukraine. (1999), no. 3. 35-39 (in Ukrainian).

Статтл: надійшла до редколегії 29.08.2019

доопрацвована 04.10.2019

прийнята до друку 13.11.2019 


\title{
ЗАУВАЖЕННЯ ДО ВІДНОСНОГО ЗРОСТАННЯ ЦІЛИХ РЯДІВ ДІРІХЛЕ
}

\author{
Оксана МУЛЯВА ${ }^{1}$, Мирослав ШЕРЕМЕТА $^{2}$ \\ ${ }^{1}$ Киӥвсъкий начіоналъний університет харчових технологій, \\ вул. Володимирівсъка, 68, 01004, Київ \\ e-mail: info@nuft.edu.ua \\ ${ }^{2}$ Лъвівсъкий начіоналъний університет імені Івана Франка, \\ вул. Університетсъка, 1, 79000, м. Лъвів \\ e-mail: m.m.sheremeta@gmail.com
}

Нехай $F$ і $G$ - цілі функції, задані рядами Діріхле зі зростаючими до $+\infty$ показниками, а $\varrho_{R}[F]_{G}-R$-порядок функції $F$ стосовно функції $G$. Величини

$T_{R}[F]_{G}:=\varlimsup_{\sigma \rightarrow+\infty} \frac{\exp \left\{M_{G}^{-1}\left(M_{F}(\sigma)\right)\right\}}{\exp \left\{\varrho_{R}[F]_{G} \sigma\right\}}, \quad t_{R}[F]_{G}:=\varliminf_{\sigma \rightarrow+\infty} \frac{\exp \left\{M_{G}^{-1}\left(M_{F}(\sigma)\right)\right\}}{\exp \left\{\varrho_{R}[F]_{G} \sigma\right\}}$ назвемо $R$-типом і нижнім $R$-типом функції $F$ відносно функції $G$. Знайдено зв'язок між $T_{R}[F]_{G}, t_{R}[F]_{G}$ і $R$-типами та нижніми $R$-типами функцій $F$ i $G$.

Ключові слова: ряд Діріхле, відносне зростання, клас збіжності. 